\title{
Atuação das sociedades musicais e bandas civis em Desterro durante o Império ${ }^{1}$
}

\author{
Marcos Holler ${ }^{2}$ \\ Débora Costa Pires ${ }^{3}$
}

RESUMO: Durante o século XIX, as bandas de música foram uma das instituições musicais mais presentes e populares no Brasil, participando de eventos sociais, sacros e profanos, militares e civis. O presente trabalho é o resultado parcial da consulta aos jornais publicados no século XIX em Desterro (atual Florianópolis), que podem ser consultados no acervo da Biblioteca Pública do Estado buscando-se informações sobre eventos musicais realizados no período, com ênfase nas bandas e sociedades musicais civis, como uma contribuição para a história da música em Santa Catarina.

PALAVRAS-CHAVE: História da Imprensa, Bandas, Sociedades Musicais, Desterro.

\section{INTRODUÇÃO}

Durante o século XIX, as bandas de música foram uma das instituições musicais mais presentes no Brasil, e no século XX transformaram-se em uma das mais populares manifestações da cultura nacional. As bandas estavam presentes em praticamente todos os eventos sociais, sacros e profanos, militares e civis; ainda hoje são um centro gerador de um vasto repertório de diversos gêneros, como chorinhos, marchas e dobrados, e nelas formam-se músicos profissionais e amadores .

A presente pesquisa tem por objetivo mapear as bandas e sociedades civis que existiam em Desterro durante o período do Império, identificando suas atuações e abrangência dentro da sociedade. As informações foram encontradas a partir de um levantamento realizado em jornais publicados em Desterro ${ }^{4}$ (atual Florianópolis), pertencentes ao acervo da Biblioteca Pública do Estado de Santa Catarina. Neste artigo não serão contempladas as bandas militares, já que o assunto se estenderia em demasiado. Cabe observar que esta pesquisa ainda está em andamento e este artigo é a

\footnotetext{
${ }^{1}$ Projeto de Pesquisa: A música na imprensa em Desterro no séc. XIX

${ }^{2}$ Doutor em Musicologia pela Universidade Estadual de Campinas (UNICAMP), professor da Universidade do Estado de Santa Catarina (UDESC).

${ }^{3}$ Graduanda do curso de Licenciatura em Música da Universidade do Estado de Santa Catarina (UDESC), bolsista PROBIC.

${ }^{4}$ Fundada no final do séc. XVII, A Vila de Nsa. Sra. do Desterro foi elevada à categoria de cidade no início do séc. XIX e em 1823 tornou-se capital da Província de Santa Catarina. Em 1894, ao fim da Revolução Federalista, teve o nome alterado para Florianópolis, como homenagem ao então Presidente da República Floriano Peixoto (PAULI, 1987). Neste artigo será mantido o nome Desterro, devido ao fato de o período abordado ser anterior à alteração do nome.
} 
apresentação do resultado parcial apurado até aqui, e os resultados finais serão apresentados posteriormente em um trabalho de conclusão de curso.

A bibliografia utilizada como fundamento para esta pesquisa e que se refere aos acervos e à história da imprensa no Estado foi a obra Nas tramas entre o público e o privado, de Joana Maria Pedro (1995), que apresenta tabelas com as publicações de jornais a partir de 1831 e informações gerais sobre sua localização nos acervos. Escrita a partir de pesquisa sobre jornais publicados em Desterro, mostra como a imprensa da época, embora vinculada a interesses privados, atuava em relação ao poder público, buscando tirar proveitos.

Sobre o período do Império foram utilizados os livros História do Brasil: o Império, 1800-1889 de Pedro Calmon (1947) e Brasil Império de Hamilton Monteiro (1990); este último aborda a história do Brasil Império tendo como eixo central a questão do autoritarismo. Também foram consultados $O$ Brasil no Império português de Janaína Amado e Luiz Carlos Figueiredo (2001) e Uma história do Brasil: Império de Mário Maestri (2001).

Sobre a história de Santa Catarina e Florianópolis foram utilizados os livros $A$ colonização de Santa Catarina (1994) e Santa Catarina: História da Gente (2003), de Walter F. Piazza, e História Sócio-Cultural de Florianópolis (1991), organizado por Osvaldo Ferreira de Melo.

Não existe ainda uma bibliografia específica sobre a história da música em Santa Catarina. Foram utilizadas algumas obras sobre a história do Estado em geral, como o Diccionario historico e geographico de Estado de Santa Catarina de José Arthur Boiteux (1940) e as obras de Oswaldo R. Cabral, A Música em Sta. Catarina no Século XIX (1951), História de Santa Catarina (1968) e Nossa Senhora do Desterro: memória (1972), obras não muito recentes e que não são fundamentados na metodologia da musicologia histórica, mas que foram um ponto de partida para a pesquisa.

Contextualizando o tema da atuação das bandas em Desterro durante o período do Império foi utilizada a dissertação de mestrado Bandas Militares no Brasil: difusão e organização entre 1808-1889 de Fernando Pereira Binder (2006), que se mostrou relevante por seu levantamento de referências bibliográficas, principalmente por ser escassa a bibliografia sobre bandas no Brasil. 


\section{HISTÓRICO DAS BANDAS NO BRASIL}

Segundo Carvalho (2006), os músicos militares no Brasil, desde os tempos coloniais, tinham um importante papel dentro da sociedade, atuando em orquestras, em sua maioria nos serviços religiosos. No século XVIII surgiram no Rio de Janeiro as primeiras bandas de música, formadas por barbeiros ou por escravos obrigados por seus senhores a aprenderem novos ofícios; essas bandas receberam a denominação de "barbeiros" porque essa profissão era a única a permitir tempo vago para aprendizagem de outros trabalhos, e tocavam fandangos, dobrados e quadrilhas em festas religiosas e profanas (DINIZ, 2007).

Alguns anos após a chegada da Família Real, em 1810, foram criadas as bandas para os regimentos de Infantaria e Cavalaria da Corte (CARVALHO, 2006). Devido à decadência do ouro no século XIX a pompa dos cerimoniais religiosos foi reduzida, provocando a diminuição no número de instrumentistas, e a dificuldade de formação de orquestras resultou na criação de bandas civis, inicialmente formadas por músicos militares (CARVALHO, 2006). Em 1831 foram criadas as bandas de música da Guarda Nacional, dando início ao desenvolvimento das bandas militares e civis nos grandes centros urbanos do Império; mais tarde surgiram as bandas civis imitando sua formação, tocando em bailes e apresentando-se nos coretos das praças (DINIZ, 2007).

As bandas civis proliferaram no fim do século XIX, ostentando nomes iniciados em geral por "Lira", "Filarmônica", “Associação", "Corporação" ou mesmo "Banda", com uniformes que remetim aos uniformes militares e com os tradicionais quepes; a partir do início do séc. XX a música das bandas perdeu espaço para outras formas de representação musical, como por exemplo os grupos de choro. (CARVALHO, 2006).

\section{BANDAS E SOCIEDADES DE MÚSICA EM DESTERRO NO SÉC. XIX}

Nos jornais são muito freqüentes as descrições da participação de bandas civis e sociedades musicais em eventos sociais profanos e sacros, litúrgicos e paralitúrgicos, em textos geralmente de autoria anônima. Uma dificuldade na leitura desses textos foi a diversidade na denominação que esses grupos recebiam na época: "filarmônica", "lira", "sociedade musical”, "associação musical” eram os mais comuns. Freqüentemente as bandas também eram chamadas de "orquestra", o que pode gerar alguma confusão na leitura de textos mais recentes, quando já existiam orquestras com uma formação intrumental diferenciadas das bandas. Outro termo também associado a bandas e que 
gera alguma confusão é "música"; da mesma forma que o termo se refere a uma banda, também denominava uma peça musical ou mesmo a uma apresentação realizada por um grupo, e nem sempre a diferenciação é clara. O termo "barbeiros" também apareceu em alguns textos: em março de 1874 o jornal A Regeneração denominou a música feita pelos músicos das bandas da província de "música de barbeiros", ofendendo alguns dos artistas e gerando críticas no jornal $O$ Conservador. Neste texto serão mantidos os termos "banda" e "sociedade musical".

Em artigo de 8 de novembro de 1874, o jornal $O$ Til cita as sociedades de baile, sociedades dramáticas e musicais existentes na província de Desterro, sendo as sociedades de baile Quatro de Março, Doze de Agosto, União Juvenil, Amor e Honra; as sociedades dramáticas Recreio Catarinense, União dos Artistas, União dos Estudantes e as sociedades musicais Filarmônica Militar, Filarmônica Comercial, Euterpe Catarinense. Em outros jornais, porém, foi possível encontrar referências a outras bandas e sociedades musicais, além de mais informações sobre as mesmas. A seguir são listadas as bandas e sociedades sobre as quais se encontrou alguma referência nos jornais; a ordem em que são apresentadas é a da data em que as referências mais antigas foram encontradas, e não de sua fundação.

Phanteon Musical: a duas únicas referências são sobre a inauguração e primeiro concerto, no jornal $O$ Despertador de 31 de Janeiro de 1868 e em $O$ Constitucional de 05 de Dezembro de 1868, respectivamente.

Club Euterpe Quatro de Março: tem sua primeira referência no dia 02 de Março de 1872, no jornal $O$ Despertador, e a última referência encontrada no mesmo jornal, de 01 de Fevereiro de 1882, que informa o desânimo pelo pequeno número de sócios e falta de dinheiro para pagar o aluguel da casa e dos dois pianos.

Philarmonica Commercial: O Conservador noticiou seu surgimento no dia 14 de outubro de 1874, e a última referência encontra-se em A Regeneração de 12 de outubro de 1884 .

Santa Cecília: tem sua primeira referência no jornal $O$ Conservador do dia 30 de janeiro de 1875, participando de um enterro junto com as bandas Trajanos e Philarmonica Commercial. A última referência foi encontrada em 16 de setembro de 1877 em A Regeneração.

Estellita: existem duas referências a esta banda, ambas no jornal Conservador. A primeira, no dia 24 de janeiro de 1875 , relata a participação da banda na festa de São 
Sebastião, e a segunda, no dia 10 de março de 1875, descreve sua participação na inauguração de uma fábrica de sabão.

Artistas Catharinenses: a única referência aparece n'O Conservador de 6 de março de 1875.

Sociedade Musical Trajano: a referência mais antiga encontra-se em $O$ Conservador de 23 de janeiro de 1875 e a mais recente no mesmo jornal, de 29 de setembro de 1885 .

Associação Musical Tymbiras: teve sua inauguração noticiada no dia 3 de abril e 1875, pel'O Conservador. A última referência aparece n' $O$ Despertador de 02 de outubro de 1875 .

Sociedade Musical Lyra Artística Catharinense: fundada em $1^{\circ}$ de agosto de 1875, segundo $O$ Despertador de 10 de agosto de 1875. A última referência aparece no mesmo jornal de 06 de Abril de 1881, que noticia a participação desta sociedade na transladação da Imagem do Senhor Jesus dos Passos.

Sociedade Guarany: surgiu de uma reformulação da Sociedade Musical Trajano, segundo o Jornal do Comércio de 11 de agosto de 1880, e teve a inauguração do seu edifício na mesma data. A referência mais recente foi encontrada na Matraca de 08 de agosto de 1885, realizando uma retreta durante a festa de Bom Jesus.

Sociedade Musical Amor à Arte: a notícia de sua instalação encontra-se em $O$ Conservador de 9 de outubro de 1875 e na Opinião Catarinense de 14 de outubro de 1875. A última referência encontrada está em $O$ Conservador de 14 de Fevereiro de 1880, que relata a participação da banda nos festejos carnavalescos. É uma das poucas bandas que ainda se encontravam ativas no momento da realização deste trabalho.

Club Harmonia Lyrica: a primeira referência aparece no dia 29 de julho de 1876 em uma nota de falecimento de um dos sócios. Os estatutos foram publicados em $O$ Conservador de 07 de outubro de 1876.

Sociedade Musical União Artística: a primeira referência surge n'Operário de 13 de agosto de 1881, que relata a participação desta sociedade nos festejos do Senhor Bom Jesus, tocando em um coreto. A última referência aparece em 15 de Maio de 1889 no jornal $O$ Despertador.

Companhia Nitheroyense: foram encontradas apenas duas referências a esta companhia, ambas sobre sua participação nos festejos em comemoração ao fim da escravidão no Brasil: nos jornais $O$ Mosquito de 27 de maio de 1888 e $O$ Crepúsculo do dia 30 de maio do mesmo ano. 
Club Estrella d'Alva: a primeira referência aparece em $O$ Despertador de 23 de outubro de 1886, que noticiou a inauguração desta sociedade no dia 31 do mesmo mês. A última referência aparece no mesmo jornal, em 28 de novembro de 1886.

Sociedade Igualdade e Fraternidade: a única referência foi encontrada em $O$ Despertador de 16 de maio de 1889.

Recreio Josephense: foram encontradas apenas duas referências nos jornais, as duas em abril de 1878, nos jornais $O$ Conservador e A Regeneração.

\section{INFORMAÇÕES ENCONTRADAS NOS JORNAIS}

Na Desterro da segunda metade do séc. XIX as bandas e sociedades musicais participavam ativamente dos mais diversos eventos, e por meio das referências nos jornais pode-se perceber a sua importância no contexto social da cidade. Não é por acaso que n'O Despertador de 17 de janeiro de 1879 há um pedido à polícia para que tomasse alguma providência contra o barulho infernal dos ensaios das sociedades de música que ocorriam até as 23 horas.

Nesse período as bandas proviam a música para praticamente todos os eventos sociais da cidade. Os bailes, oferecidos com frequiência, eram animados por esses grupos. Por exemplo, segundo O Constitucional de 18 de setembro de 1867 o Sr. Dr. Affonso de Mello recebeu o "Illm. Sr. Dr. Fernando Maranhense da Cunha (ex-juiz de direito da comarca de Viçosa) em sua casa, oferecendo um baile, acompanhado por uma banda de música". O Conservador de 28 de abril de 1875 noticia sobre baile oferecido ao ex-presidente da província, João Thomé da Silva, aberto pela banda de música Trajano. As bandas também participavam do carnaval, unindo-se às sociedades carnavalescas; a referência mais antiga a uma união como esta encontra-se n'O Catarinense de 23 fevereiro de 1861. As retretas e apresentações tinham grande importância dentro da província, animando a vida social. O jornal $O$ Conservador de fevereiro de 1876 escreve sobre a costumeira retreta da Sociedade Trajano, durante a qual foi executado $O$ Canto dos Aventureiros, da ópera $O$ Guarani, de Carlos Gomes. Em outubro de 1876, o jornal $O$ Conservador escreveu que a banda da sociedade Trajano percorreu em passeio as principais ruas da cidade, executando marchas e dobrados. No mesmo ano, segundo $O$ Despertador, a sociedade Philarmonica Commercial festejou nos salões do Club Quatro de Março o seu segundo aniversário e a banda marcial da sociedade tocou uma retreta à noite. Outros eventos sociais também 
contavam com a participação das bandas, como por exemplo a inauguração de uma fábrica de sabão descrita nos jornais $O$ Conservador e $O$ Despertador de março de 1875, com a presença das bandas de música Trajano e Estellita.

Existem também relatos da participação das bandas e sociedades musicais em enterros. N'O Conservador de 30 de janeiro de 1875 encontra-se o agradecimento de um familiar às pessoas que acompanharam o enterro de sua mãe, em especial às sociedades musicais Santa Cecília, Philarmonica Comercial e Trajanos. Em maio de 1876, segundo $O$ Conservador, a banda de música Amor à Arte teria tocado no funeral de um dos integrantes.

As bandas e sociedades musicais também tinham ligação com o teatro em Desterro, participando nas representações ou nos intervalos das peças teatrais. Em setembro de 1875, o jornal $O$ Conservador noticiou que a sociedade dramática Recreio Catharinense organizou o espetáculo de sua inauguração, do qual participaram as sociedades musicais Santa Cecília e Philarmonica Comercial. Em dezembro do mesmo ano, um artigo n'O Conservador elogiou o espetáculo apresentado no teatro Santa Isabel por ocasião do aniversário do Imperador, durante o qual teria tocado a Sociedade Musical Santa Cecília. Em setembro de 1877 o jornal A Regeneração noticiou um grande e variado espetáculo de trabalhos do Oriente, depois do qual teria sido executada uma sinfonia pela banda de música.

Também nas comemorações cívicas é possível observar a participação dos grupos musicais civis, tocando lado a lado com as bandas militares ou mesmo substituindo-as; percebe-se que os grupos civis ocupavam um espaço que as bandas militares não podiam ou não desejavam ocupar. Em 25 janeiro de 1871, o jornal $A$ Província relatou a posse do novo Presidente da Província, com a participação de uma banda militar tocando o Hino Nacional; depois disso a mesma banda foi para a casa do presidente do partido conservador onde se juntou a uma outra banda de música particular. Em seguida as duas bandas se dirigiram à residência de outro político e continuaram dando seu espetáculo. O mesmo jornal, em fevereiro de 1871, relata que o presidente do diretório do grêmio do partido conservador ofereceu, em sua casa, um jantar para comemorar a eleição do novo diretório, e uma banda de música tocou durante todo o evento. Em outubro do mesmo ano aconteceram as eleições e existem referências a uma "música particular" que teria tocado durante estas comemorações. Em março de 1886, como comemoração pela vitória do Partido Conservador nas eleições, membros do Partido percorreram as ruas da cidade precedidos pela banda de música 
União dos Artistas; no mesmo jornal, em agosto de 1888, há o relato da participação da mesma banda de música na comemoração pela eleição de um deputado republicano em Minas Gerais.

As bandas civis também participavam de eventos sacros na cidade, tanto litúrgicos quanto paralitúrgicos. Nas missas, sobretudo em ocasiões especiais, a presença das bandas era constante: $O$ Conservador de 31 de março de 1875 relata a participação das bandas de música Trajanos e Santa Cecília nos atos da Semana Santa, e no mesmo jornal, em 17 de abril de 1875, está noticiada a participação voluntária da Philarmonica Santa Cecília no acompanhamento das missas de domingo. Segundo o jornal, este era um serviço que os jovens faziam por amor à religião. Em 21 de Junho de 1884 o jornal $O$ Despertador anunciou uma missa e Te Deum na capela de São Sebastião, por causa da epidemia na capital, com a participação das sociedades de música Trajanos e União Artística.

Procissões eram geralmente acompanhadas por bandas: $O$ Conservador do dia 19 de abril de 1876 descreveu as procissões da Semana Santa com a participação de bandas e sociedades musicais de Desterro. Em abril de 1878, os jornais O Despertador, $O$ Conservador e A Regeneração noticiaram a participação das bandas Recreio Josephense, Lyra Artística Catharinense, Amor à Arte, Philarmonica Commercial e Trajano tocando durante o trajeto da procissão do Senhor dos Passos. Em abril de 1881 a procissão da Imagem do Senhor Jesus dos Passos não teve guarda de honra por não haver tropa disponível, porém as sociedades Commercial, Guarany e Lyra Artística compareceram na execução de marchas.

Festas de oragos eram extremamente comuns em Desterro no séc. XIX, também contando com a presença das bandas, às vezes de mais de uma ao mesmo tempo. No jornal $O$ Conservador de 23 de janeiro de 1875, há o relato sobre a participação de duas bandas, uma delas a Trajanos, na festa de São Sebastião. Também se reportando à festa de São Sebastião, o jornal $O$ Til de 24 de janeiro de 1875 apresenta um artigo cujo autor descreve o silêncio durante o trajeto da transladação, que teria sido interrompido pelos sons de três bandas de música. Ainda no jornal $O$ Conservador, de 14 de agosto de 1875, há um anúncio da festa em comemoração à padroeira da freguesia do Ribeirão, sendo que a Sociedade Musical Trajanos teria ficado responsável por animar a festa. $\mathrm{O}$ jornal $O$ Conservador de 15 de setembro de 1875 descreveu a festa do orago em Santo Antônio: as bandas musicais Santa Cecília e Tymbiras teriam tocado gratuitamente, na igreja e pelas ruas da freguesia, "com gosto e proficiência". No mesmo jornal do dia 27 
de outubro de 1875, há o relato da participação da Sociedade Musical Amor à Arte na festa de Nossa Senhora do Rosário, na freguesia do Ribeirão. Em 08 de dezembro de 1875 há o relato sobre a missa de São Joaquim, onde teria tocado nos intervalos a Sociedade Musical Trajanos. O ano de 1880 iniciou-se com a festa de Nossa Senhora das Dores com a participação da Sociedade Musical Lyra Artística, tocando junto com uma banda militar.

\section{CONSIDERAÇÕES FINAIS}

No Brasil do séc. XIX as bandas de música faziam parte de um imaginário no qual tais conjuntos eram símbolos sonoros de poder e status. Este imaginário dava sentido à atuação das bandas, justificando a existência e criação dos conjuntos (BINDER, 2006, p. 126). O levantamento realizado nos jornais permitiu a identificação das bandas e sociedades musicais que atuavam na segunda metade do séc. XIX em Desterro, e por meio desse levantamento pode-se também perceber a importância desses grupos no contexto social da sociedade desterrense do período. Alguns desses grupos continuam ativos ainda hoje, como no caso da Sociedade Musical Amor à Arte, que mantém um arquivo com documentos de sua história.

Os grupos civis de música atuavam no espaço que muitas vezes não podia ser ocupado pelas bandas militares. Com isso, tocavam nos mais diversos espaços e festividades, tanto profanos, litúrgicos e até mesmo em conjunto com as bandas militares, participando ativamente da sociedade desterrense, contribuindo em eventos musicais e nas manifestações artístico-musicais.

Este artigo, como dito anteriormente, provém de uma pesquisa em andamento e existe ainda a necessidade de novos estudos e reflexões sobre o tema, e algumas dessas questões serão aprofundadas em um trabalho de conclusão de curso.

\section{REFERÊNCIAS}

AMADO, Janaína; FIGUEIREDO, Luiz Carlos. O Brasil no Império português. Rio de janeiro: Jorge Zahar Ed., 2001.

BINDER, Fernando Pereira. Bandas Militares no Brasil: difusão e organização entre 1808-1889. Dissertação de Mestrado. Universidade Estadual Paulista. 2006. 
BOITEUX, Jose Arthur (org). Diccionario historico e geographico de Estado de Santa Catarina. Florianópolis: Imprensa Oficial do Estado, 1940.

CABRAL, Oswaldo Rodrigues. História de Santa Catarina. Florianópolis: Imprensa da Universidade Federal de Santa Catarina, 1968.

. Nossa Senhora do Desterro: memória. Florianópolis: Imprensa da

Universidade Federal de Santa Catarina, 1972.

. A Música em Sta. Catarina no Século XIX. Florianópolis: [s.e.], 1951.

CALMON, Pedro. História do Brasil: o Império, 1800-1889. São Paulo: Ed. Nacional, 1947.

CARVAlHO, Vinícius Mariano de. História e tradição da Música Militar. Disponível em: < http://www.defesa.ufjf.br/fts/musicamilitar.pdf>. Acesso em: 14 jan. 2008.

DINIZ, André. A Formação da Música Popular Carioca: Bandas e Chorões. Curso On-line. Jun. 2007. Disponível em: < http://www.niteroiartes.com.br/cursos/muspop/ modulo1.php>. Acesso em: 05 jul. 2008.

HARO, Martim Afonso Palma de Haro (org). Ilha de Santa Catarina:Relato de viajantes estrangeiros nos séculos XVIII e XIX. Florianópolis: Editora Lunardelli, 1996.

MAESTRI, Mário. Uma história do Brasil: Império. São Paulo: Contexto, 2001.

MELO, Osvaldo Ferreira de (org). História Sócio-Cultural de Florianópolis.

Florianópolis: Lunardelli, 1991.

MONTEIRO, Hamilton de Matos. Brasil Império. São Paulo: Ed. Ática,1990.

PAULI, Evaldo. A fundação de Florianópolis. 2. ed. Florianópolis: Lunardelli, 1987.

PEDRO, Maria Joana. Nas tramas entre o público e o privado: a imprensa de Desterro, 1831-1889. Florianópolis: Editora da UFSC, 1995.

PIAZZA, Walter Fernando. A colonização de Santa Catarina. 3. ed. Florianópolis: Lunardelli, 1994.

Lunardelli, 2003.

Santa Catarina: História da Gente. 6. ed. Florianópolis:

JORNAIS

A Estrella. Desterro, 1861.

A Província. Desterro, 1870 a 1872.

A Regeneração. Desterro, 1868 a 1889. 
Commercial. Desterro, 1868.

Conservador. Desterro, 1884 a 1889.

Jornal do Comércio. Desterro, 1880 a 1894.

Matraca. Desterro, 1881 a 1888.

O Caixeiro. Desterro, 1881 a 1882.

O Catarinense. Desterro, 1860 a 1861.

O Conciliador. Desterro, 1872 a 1873.

O Conciliador Catarinense. Desterro, 1849 a 1851.

O Conservador. Desterro, 1852 a 1855.

O Conservador. Desterro, 1871 a 1883.

O Constitucional. Desterro, 1867 a 1868.

O Correio Oficial. Desterro, 1860 a 1861.

O Crepúsculo. Desterro, 1887 a 1889.

O Cruzeiro do Sul. Desterro, 1858 a 1860.

O Despertador. Desterro, 1863 a 1885.

O Mercantil. Desterro, 1861 a 1869.

O Mosquito. Desterro, 1888 a 1889.

O Operário. Desterro, 1881.

Opinião Catarinense. Desterro, 1874 a 1875.

O Santelmo. Desterro, 1858.

O Til. Desterro, 1874 a 1875.

Província. Desterro, 1882. 